\title{
Influence of Bottom Ash Replacements as Fine Aggregate on the Property of Cellular Concrete with Various Foam Contents
}

\author{
Patchara Onprom, Krit Chaimoon, and Raungrut Cheerarot \\ Concrete and Computer Research Unit, Field of Civil Engineering, Faculty of Engineering, Mahasarakham University, \\ Mahasarakham 44150, Thailand \\ Correspondence should be addressed to Raungrut Cheerarot; raungrut@hotmail.com
}

Received 28 August 2015; Revised 24 October 2015; Accepted 28 October 2015

Academic Editor: Belal F. Yousif

Copyright (C) 2015 Patchara Onprom et al. This is an open access article distributed under the Creative Commons Attribution License, which permits unrestricted use, distribution, and reproduction in any medium, provided the original work is properly cited.

\begin{abstract}
This research focuses on evaluating the feasibility of utilizing bottom ash from coal burning power plants as a fine aggregate in cellular concrete with various foam contents. Flows of all mixtures were controlled within $45 \pm 5 \%$ and used foam content at $30 \%$, $40 \%, 50 \%, 60 \%$, and $70 \%$ by volume of mixture. Bottom ash from Mae Moh power plant in Thailand was used to replace river sand at the rates of $0 \%, 25 \%, 50 \%, 75 \%$, and $100 \%$ by volume of sand. Compressive strength, water absorption, and density of cellular concretes were determined at the ages of 7, 14, and 28 days. Nonlinear regression technique was developed to construct the mathematical models for predicting the compressive strength, water absorption, and density of cellular concrete. The results revealed that the density of cellular concrete decreased while the water absorption increased with an increase in replacement level of bottom ash. From the experimental results, it can be concluded that bottom ash can be used as fine aggregate in the cellular concrete. In addition, the nonlinear regression models give very high degree of accuracy $\left(R^{2}>0.99\right)$.
\end{abstract}

\section{Introduction}

In recent years, cellular concrete has increasingly been used in construction because it has an advantage of reducing the sizes of structures. Cellular concrete or foam concrete is a lightweight material consisting of Portland cement paste or cement filler matrix (mortar) with homogeneous voids or pore structures created by introducing air in the form of small bubbles. Introduction of pores is achieved through mechanical means either by preformed foaming or mix foaming. Preformed foaming is preferred to mix-forming technique due to the following advantages: (1) a lower foaming agent requirement and (2) a close relationship between amount of foaming agent used and air content of mix [1-3]. Generally, cellular concrete can be classified into two types: autoclave and nonautoclave cellular concrete. High-pressure steam curing makes the autoclave cellular concrete to improve the quality in lighter weight, low thermal conductivity, high heat resistance, and low drying shrinkage. The cellular concrete is widely used in the construction industry due to its lightweight and favorable insulation properties which are suitable for materials of sound barriers, fire walls, and building panels [4].

The use of industrial waste and byproduct materials is now widely recognized as one of the preferred options towards the achievement of sustainable development [5]. Bottom ash (BA) is a byproduct of the combustion of pulverized coal in the power plants. From the previous studies, BA was used mainly on concrete block and road constructions and it was applied as lightweight aggregate in mortar and concrete [6], where the results indicated that BA can be applied as a construction material. Some studies had progressed slowly focusing on the possibility of BA as sand replacement in normal concrete [7-9]. In addition, it was used as fine and coarse aggregate in high-strength concrete [10]. The results indicated that the slump flow of fresh concrete was slightly decreased when coarse BA was replaced at $100 \%$ of normal coarse aggregate. In Thailand, Mae Moh power plants produce BA approximately 2,000 tons a day or about $20 \%$ by volume of the total ash [11]. Most of the BA has been disposed in landfills because its uses are 
TABLE 1: Physical and chemical properties of materials.

\begin{tabular}{lccc}
\hline & Cement & Sand & Bottom ash \\
\hline Physical properties & & & \\
Specific gravity & 3.14 & 2.56 & 2.10 \\
Absorption (\%) & - & 1.21 & 6.18 \\
Moisture content (\%) & - & 0.47 & 0.43 \\
Voids (\%) & - & 34.6 & 46.8 \\
Fineness modulus & - & 2.76 & 2.10 \\
Blaine fineness (cm $\left.{ }^{2} / g\right)$ & 3,270 & - & - \\
Median particle size (micron) & 13.0 & - & 290 \\
$\mathrm{Retained} \mathrm{on} \mathrm{sieve} \mathrm{number} \mathrm{325} \mathrm{( \% )}$ & 10.8 & - & 94.5 \\
$\mathrm{Chemical} \mathrm{composition} \mathrm{( \% )}$ & & & \\
$\mathrm{SiO}_{2}$ & 20.62 & 92.86 & 46.02 \\
$\mathrm{Al}_{2} \mathrm{O}_{3}$ & 5.22 & 3.17 & 22.31 \\
$\mathrm{Fe}_{2} \mathrm{O}_{3}$ & 3.10 & 0.27 & 10.64 \\
$\mathrm{CaO}_{\mathrm{MgO}}$ & 65.00 & 0.55 & 11.48 \\
$\mathrm{~K}_{2} \mathrm{O}$ & 0.91 & 0.49 & 3.45 \\
$\mathrm{Na}_{2} \mathrm{O}$ & 0.07 & 0.32 & 2.37 \\
$\mathrm{SO}_{3}$ & 0.50 & 0.42 & 0.07 \\
$\mathrm{LOI}$ & 2.70 & 0.55 & 1.76 \\
\hline
\end{tabular}

limited, leading to increases of landfills results in greater air and environment pollution problems. In addition, these are several advantages of use of BA in the cellular concrete, that is, cost saving and reduction in the use of natural sand, disposal of wastes, prevention of environmental pollution, and energy saving. Moreover, high porous BA particles may reduce the shrinkage which was found in using lightweight aggregate in foam concrete [12].

\section{Experimental Program}

2.1. Materials. The physical properties of materials were shown in Table 1. Ordinary Portland Cement (OPC) with specific gravity of 3.14 and Blaine fineness of $3,270 \mathrm{~cm}^{2} / \mathrm{g}$ was used in all cellular concrete mixtures. Local river sand (SA) having a specific gravity of 2.56 and BA specific gravity of 2.10 from Mae Moh power plant in the north of Thailand were used in this research as fine aggregate. Both SA and BA were sieved through sieve number 16 and retained on sieve number 100.

Figure 1 shows the scanning electron microscope (SEM) of BA. The particle shape of BA is irregular and porous. However, the particle size distributions of the combinations of SA and BA in this research indicated by the gradation curves meet most of the requirement of ASTM C 33 (in Figure 2). The chemical properties of both materials are also reported in Table 1 . The major chemical compositions of Portland cement, $\mathrm{SA}$, and $\mathrm{BA}$ were $\mathrm{CaO}$ (65.00\%), $\mathrm{SiO}_{2}$ (92.86\%), and $\mathrm{SiO}_{2}(46.02 \%)$, respectively.

2.2. Mix Proportions. The mix proportions of cellular concrete are given in Table 2. Different mixes of cellular concrete were made by use of foam content $(\mathrm{V})$ at $30 \%, 40 \%, 50 \%$,
TABLE 2: Mix proportions of cellular concrete.

\begin{tabular}{|c|c|c|c|c|c|}
\hline \multirow{2}{*}{ Mixture } & \multicolumn{5}{|c|}{ Mix proportions (by volume, $\mathrm{m}^{3}$ ) } \\
\hline & Cement & Sand & Water & Foam content & Bottom ash \\
\hline $30 \mathrm{~V} 0 \mathrm{BA}$ & 0.175 & 0.215 & 0.310 & 0.3 & 0 \\
\hline $30 \mathrm{~V} 25 \mathrm{BA}$ & 0.166 & 0.161 & 0.318 & 0.3 & 0.054 \\
\hline 30V50BA & 0.158 & 0.108 & 0.327 & 0.3 & 0.108 \\
\hline 30V75BA & 0.150 & 0.054 & 0.335 & 0.3 & 0.161 \\
\hline 30V100BA & 0.142 & 0 & 0.343 & 0.3 & 0.215 \\
\hline 40V0BA & 0.151 & 0.185 & 0.264 & 0.4 & 0 \\
\hline $40 \mathrm{~V} 25 \mathrm{BA}$ & 0.144 & 0.139 & 0.271 & 0.4 & 0.046 \\
\hline 40V50BA & 0.136 & 0.093 & 0.278 & 0.4 & 0.093 \\
\hline 40V75BA & 0.129 & 0.046 & 0.285 & 0.4 & 0.139 \\
\hline 40V100BA & 0.123 & 0 & 0.292 & 0.4 & 0.185 \\
\hline 50V0BA & 0.127 & 0.155 & 0.218 & 0.5 & 0 \\
\hline $50 \mathrm{~V} 25 \mathrm{BA}$ & 0.121 & 0.116 & 0.224 & 0.5 & 0.039 \\
\hline $50 \mathrm{~V} 50 \mathrm{BA}$ & 0.115 & 0.078 & 0.229 & 0.5 & 0.078 \\
\hline 50V75BA & 0.110 & 0.039 & 0.235 & 0.5 & 0.116 \\
\hline 50V100BA & 0.104 & 0 & 0.241 & 0.5 & 0.155 \\
\hline $60 \mathrm{~V} 0 \mathrm{BA}$ & 0.103 & 0.126 & 0.172 & 0.6 & 0 \\
\hline $60 \mathrm{~V} 25 \mathrm{BA}$ & 0.097 & 0.095 & 0.177 & 0.6 & 0.032 \\
\hline $60 \mathrm{~V} 50 \mathrm{BA}$ & 0.092 & 0.063 & 0.182 & 0.6 & 0.063 \\
\hline $60 \mathrm{~V} 75 \mathrm{BA}$ & 0.087 & 0.032 & 0.187 & 0.6 & 0.095 \\
\hline $60 \mathrm{~V} 100 \mathrm{BA}$ & 0.083 & 0 & 0.191 & 0.6 & 0.126 \\
\hline $70 \mathrm{~V} 0 \mathrm{BA}$ & 0.079 & 0.097 & 0.126 & 0.7 & 0 \\
\hline $70 \mathrm{~V} 25 \mathrm{BA}$ & 0.074 & 0.073 & 0.130 & 0.7 & 0.024 \\
\hline 70V50BA & 0.069 & 0.049 & 0.134 & 0.7 & 0.049 \\
\hline 70V75BA & 0.066 & 0.024 & 0.137 & 0.7 & 0.073 \\
\hline 70V100BA & 0.062 & 0 & 0.141 & 0.7 & 0.097 \\
\hline
\end{tabular}

Note: 30, 40, 50, 60, 70: percentage of foam content, V: foam content, 0,25 , $50,75,100$ : percentage of bottom ash, and BA: bottom ash.

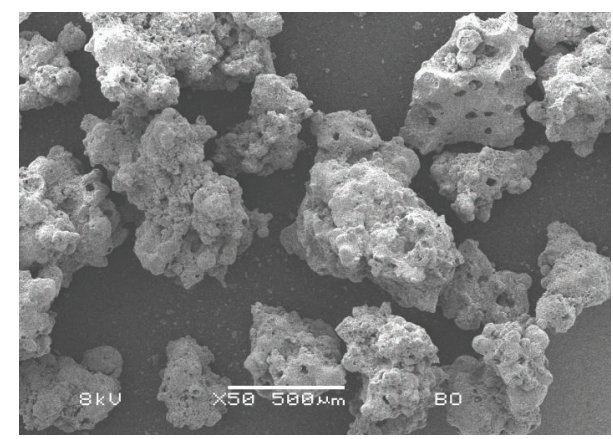

FIGURE 1: SEM of original bottom ash observed at magnification 50x.

$60 \%$, and $70 \%$ by volume of mixture and the aggregate to binder ratio at $1: 1$ by weight and original $\mathrm{BA}$ replacement for SA at the rates of $0,25,50,75$, and $100 \%$ by volume of sand. Foam was produced by aerating an organic based foaming agent. The foaming agent was diluted with water in ratio of $1: 30$ by volume and then poured into an indigenously fabricated foam generator to produce foam with a density of $50 \mathrm{~kg} / \mathrm{m}^{3}$. Cellular concrete was produced in laboratory by using a paddle mixer with adding of foam into a mortar mix 


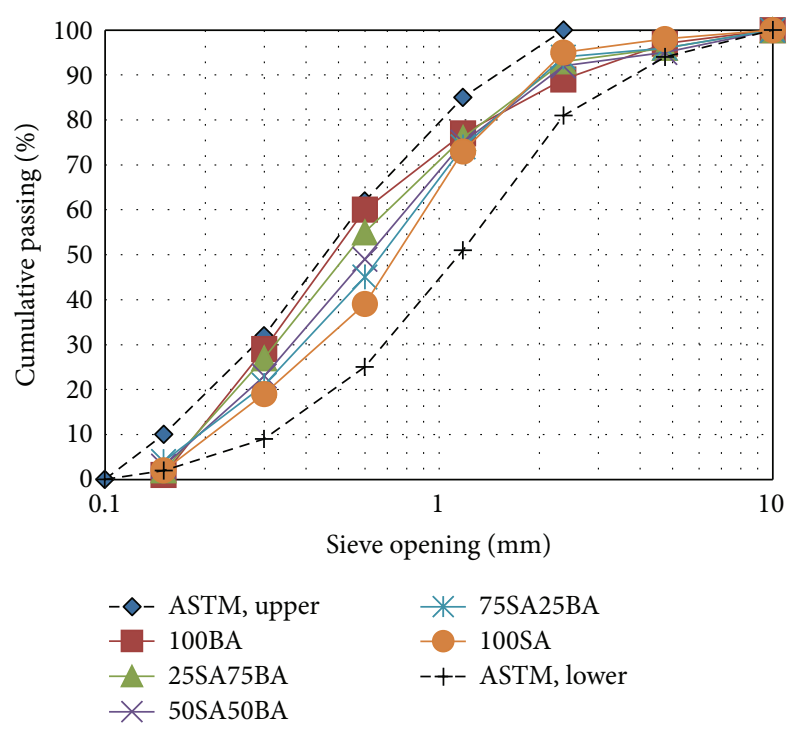

FIGURE 2: Particle size distributions of SA, BA, and combinations.

(cement-sand or cement-sand-bottom ash). The sequence of mixing starts with combining the cement and fine aggregate with water and keep mixing until a homogeneous mortar is obtained. After that, foam volume was added in the mortar and mixed for a minimum duration until foam was uniformly distributed.

2.3. Testing Details. Based on several trails, the percent flows (consistency), measured in a standard flow table and in accordance with ASTM C 230 (without raising/dropping of the flow table as it may affect the foam bubbles entrained in the mix), were arrived at as $45 \pm 5 \%$. Earlier studies showed that, within this range, it gives a good stability and consistency $[13,14]$. After that, the specimens were removed from the mold after 24 hours. The compressive strength, water absorption, and density at specific ages were determined.

The compressive strength was measured by three $50 \mathrm{~mm}$ cubes at 7, 14, and 28 days, in accordance with ASTM C 109. Water absorption is usually measured by drying the specimen to constant mass, immersing it in water and measuring the increase in mass as a percentage of dry mass. Density is defined as mass divided by volume. All testing was measured on 3 cube specimens with size of $50 \mathrm{~mm}$ for each mix of cellular concrete after moist curing. An average of the three values at each age was calculated.

The morphology and microstructure analysis of cellular concrete were characterized using scanning electron microscope (SEM) images and electron dispersive X-ray (EDX) spectrum with $15 \mathrm{kV}$, respectively. Gold-coated samples were used to examine fracture surfaces.

\section{Results and Discussion}

3.1. Water Requirements. The water requirements for achieving a stable and workable of cellular concretes are also shown in Table 2. It was found that the water requirement increases

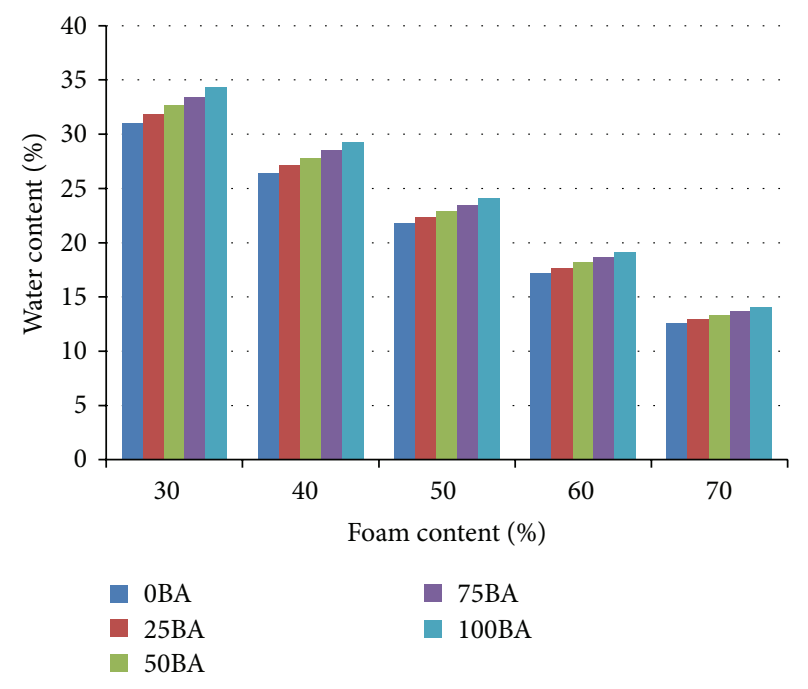

FIgURE 3: Water content of cellular concrete.

with an increase in the level of sand replacement by BA. For example, the water content of 50V0BA, 50V25BA, 50V50BA, $50 \mathrm{~V} 75 \mathrm{BA}$, and 50V100BA was $0.218,0.224,0.229,0.235$, and $0.241 \mathrm{~m}^{3}$, respectively. This was due to the increase of porosity in cellular concrete. Similar results have been reported on a study of concrete using bottom ash as sand in literature [15]. And some literature explained that this was due to the high porosity of BA which absorbed water and resulted in high water requirements [11]. In contrary, the increase of foam content resulted in a decrease of water content because of its lower solid content which can be seen in Figure 3 .

3.2. Compressive Strength. Compressive strength is one of the most important properties of concrete. Many researches showed that the compressive strength inversed the density of cellular concrete [12-14]. Table 3 tabulates the compressive strength of cellular concrete and Figure 4 presents some of the relationship among compressive strength and important parameters. The compressive strength of 30V0BA, $40 \mathrm{~V} 0 \mathrm{BA}, 50 \mathrm{~V} 0 \mathrm{BA}, 60 \mathrm{~V} 0 \mathrm{BA}$, and 70V0BA at 28 days were $5.2,4.0,2.8,2.0$, and $1.7 \mathrm{MPa}$, respectively. It was found that compressive strength depended on foam content, percent sand replacement by BA, and curing age where the cellular concretes with the higher foam gave the lower compressive strength. The cellular concrete with foam content less than $50 \%$ gave the compressive strength more than $2.5 \mathrm{MPa}$ (as TIS 1505-1998 specification). The replacement of SA by BA decreased cement content in cellular concrete, thus resulting in lower compressive strength the same as the results of cellular concrete using higher foam content. For example, the compressive strength at 28 days of cellular concretes $50 \mathrm{~V} 0 \mathrm{BA}, 50 \mathrm{~V} 25 \mathrm{BA}, 50 \mathrm{~V} 50 \mathrm{BA}, 50 \mathrm{~V} 75 \mathrm{BA}$, and 50V100BA was $2.8,2.8,2.3,1.9$, and $1.7 \mathrm{MPa}$, respectively. It can be seen that the use of $25 \%$ of sand replacement by BA gave similarly compressive strength of $0 \%$ of sand replacement (not use $\mathrm{BA}$ ). For mixes with BA, compressive strength decreases with increasing of BA content because increasing of water content and pore number in cellular concrete will induce a decrease 
TABLE 3: Compressive strength, water absorption, and density of cellular concretes.

\begin{tabular}{|c|c|c|c|c|c|c|c|c|c|}
\hline \multirow{2}{*}{ Mixture } & \multicolumn{3}{|c|}{ Compressive strength (MPa) } & \multicolumn{3}{|c|}{ Water absorption (\%) } & \multicolumn{3}{|c|}{ Density $\left(\mathrm{kg} / \mathrm{m}^{3}\right)$} \\
\hline & 7 days & 14 days & 28 days & 7 days & 14 days & 28 days & 7 days & 14 days & 28 days \\
\hline 30V0BA & 4.4 & 4.8 & 5.2 & 20 & 20 & 19 & 1336 & 1332 & 1296 \\
\hline $30 \mathrm{~V} 25 \mathrm{BA}$ & 4.2 & 4.5 & 5.0 & 22 & 23 & 22 & 1270 & 1280 & 1165 \\
\hline 30V50BA & 3.5 & 3.8 & 4.2 & 25 & 26 & 25 & 1248 & 1244 & 1241 \\
\hline 30V75BA & 2.9 & 3.2 & 3.4 & 27 & 28 & 27 & 1180 & 1178 & 1171 \\
\hline 30V100BA & 2.6 & 2.9 & 3.1 & 31 & 31 & 30 & 1141 & 1138 & 1142 \\
\hline 40V0BA & 3.6 & 3.8 & 4.0 & 21 & 21 & 20 & 1184 & 1180 & 1176 \\
\hline 40V25BA & 3.3 & 3.6 & 4.1 & 24 & 24 & 23 & 1151 & 1148 & 1142 \\
\hline 40V50BA & 2.6 & 3.0 & 3.2 & 28 & 27 & 27 & 1112 & 1121 & 1118 \\
\hline 40V75BA & 2.2 & 2.4 & 2.6 & 32 & 31 & 31 & 1065 & 1072 & 1068 \\
\hline 40V100BA & 2.0 & 2.5 & 2.6 & 35 & 36 & 35 & 1012 & 1010 & 1008 \\
\hline $50 \mathrm{~V} 0 \mathrm{BA}$ & 2.5 & 2.6 & 2.8 & 23 & 23 & 23 & 1064 & 1034 & 999 \\
\hline $50 \mathrm{~V} 25 \mathrm{BA}$ & 2.5 & 2.7 & 2.8 & 28 & 27 & 28 & 1032 & 995 & 984 \\
\hline 50V50BA & 1.8 & 2.0 & 2.3 & 35 & 34 & 34 & 1000 & 984 & 968 \\
\hline 50V75BA & 1.6 & 1.7 & 1.9 & 37 & 35 & 36 & 924 & 883 & 856 \\
\hline 50V100BA & 1.5 & 1.6 & 1.7 & 39 & 38 & 38 & 904 & 884 & 840 \\
\hline 60V0BA & 1.7 & 1.8 & 2.0 & 26 & 26 & 27 & 960 & 892 & 832 \\
\hline $60 \mathrm{~V} 25 \mathrm{BA}$ & 1.7 & 1.9 & 2.1 & 32 & 33 & 33 & 885 & 861 & 855 \\
\hline $60 \mathrm{~V} 50 \mathrm{BA}$ & 1.4 & 1.4 & 1.6 & 38 & 38 & 37 & 832 & 835 & 827 \\
\hline $60 \mathrm{~V} 75 \mathrm{BA}$ & 1.2 & 1.3 & 1.4 & 42 & 43 & 43 & 804 & 811 & 798 \\
\hline $60 \mathrm{~V} 100 \mathrm{BA}$ & 1.1 & 1.1 & 1.2 & 45 & 46 & 46 & 766 & 755 & 762 \\
\hline 70V0BA & 1.4 & 1.6 & 1.7 & 40 & 38 & 38 & 816 & 818 & 808 \\
\hline 70V25BA & 1.5 & 1.5 & 1.7 & 42 & 42 & 44 & 795 & 791 & 797 \\
\hline 70V50BA & 1.2 & 1.4 & 1.5 & 48 & 49 & 49 & 774 & 765 & 761 \\
\hline 70V75BA & 0.9 & 1.0 & 1.0 & 52 & 53 & 53 & 740 & 738 & 735 \\
\hline 70V100BA & 0.8 & 0.9 & 1.0 & 56 & 55 & 56 & 711 & 708 & 704 \\
\hline
\end{tabular}

of compressive strength. Similar results have been reported on a study of compressive strength of lightweight concrete in literature $[16,17]$. However, $\mathrm{BA}$ is one of pozzolanic materials and thus it can react $\mathrm{Ca}(\mathrm{OH})_{2}$ from hydration reaction to produce $\mathrm{CSH}$ and $\mathrm{CAH}$ which can enhance compressive strength of concrete [11].

3.3. Water Absorption. From Figure 5, it was found that an increase in the level of replacement of SA by BA and foam content leads to increase of water absorption. For example, the water absorptions at 7 days of cellular concretes 30V0BA, 30V25BA, 30V50BA, 30V75BA, and 30V100BA were 20, 22, 25,27 , and $31 \%$ while the water absorptions at 7 days of cellular concretes 70V0BA, 70V25BA, 70V50BA, 70V75BA, and 0V100BA were $40,42,48,52$, and $56 \%$, respectively. A relatively higher water-solids ratio produces a weaker and pervious matrix, leading to higher capillary porosity which is in turn responsible for the increase in water absorption of mixes with BA. Similar results have been reported on water absorption of foam concrete using fly ash as sand in the literature of Nambiar and Ramamurthy [18].
3.4. Density. Figure 6 indicates that an increase of BA content leads to decrease of density of cellular concrete due to its low specific gravity (2.10) compared with SA (2.56). As a result, BA replacement for SA at $100 \%$ by volume reduced density approximately $15 \%$ by weight. Use of foam content more than $50 \%$ gave the density lower than $1,000 \mathrm{~kg} / \mathrm{m}^{3}$. However, it can be seen that when the compressive strength and density are higher, the water absorption is lower (as Table 3). From Table 3, it showed that the mixes that had the compressive strength more than $2.5 \mathrm{MPa}$ and the water absorption less than $30 \%$ and the density less than $1,000 \mathrm{~kg} / \mathrm{m}^{3}$ were cellular concretes 50V0BA and 50V25BA where cellular concrete 50V25BA was selected as the optimum mix because it had the lower density.

With the current results, it could be concluded that $25 \%$ of the BA as SA and $50 \%$ of foam content (50V25BA) were the optimum of BA content due to the compressive strength, density, and water absorption comparable to that of the control cellular concrete. In addition, it was found that the compressive strength of cellular concrete is equal to class 2 of aerated lightweight concrete by Thai Industrial Standards 


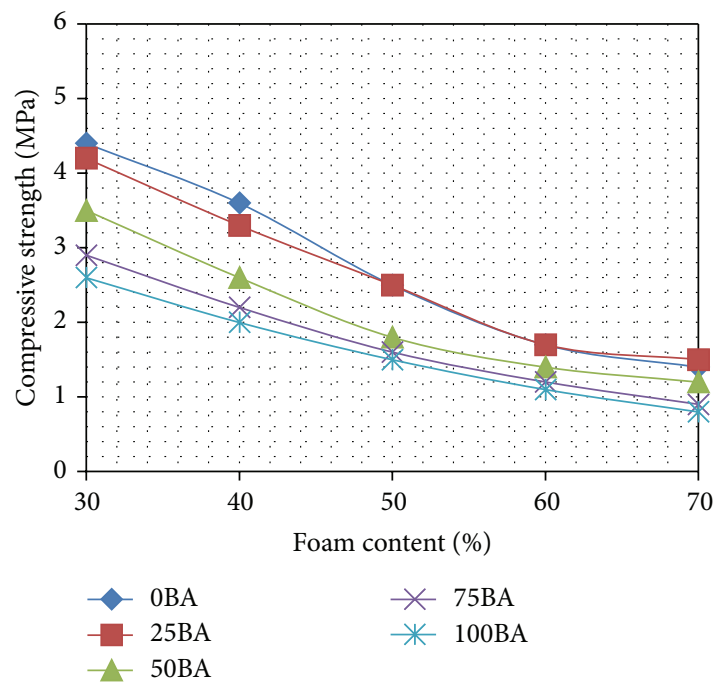

(a) 7 days

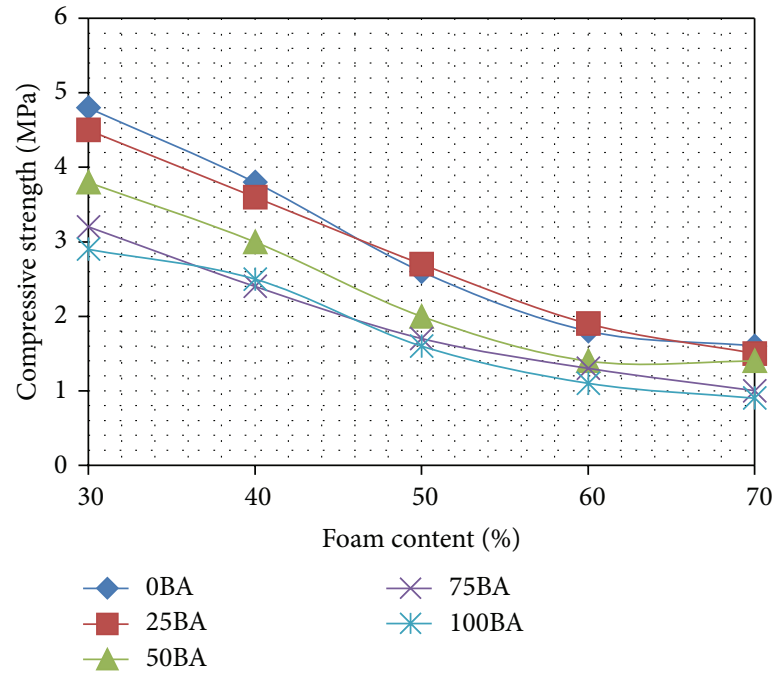

(b) 14 days

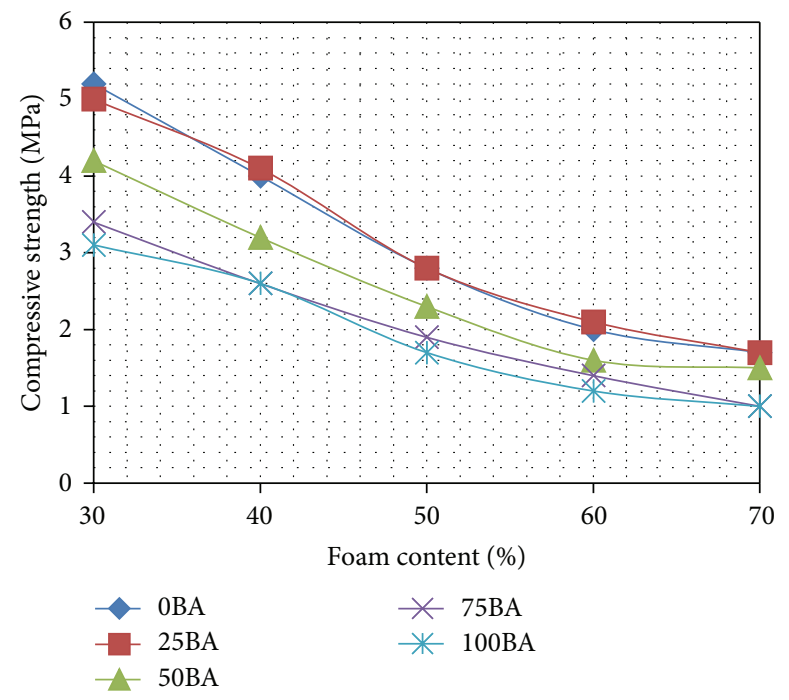

(c) 28 days

FIGURE 4: The compressive strength of cellular concrete.

(TIS) 1505 and $2601[19,20]$. However, the density of BA cellular concrete is higher than that of the TIS standard. Although the density obtained from cellular concrete containing 50V25BA is higher than for TIS standard, nevertheless, the density of this study is lower than typical clay brick in Thailand's Construction Industry. Furthermore, its compressive strength in this research meets most the required clay brick strength. These comparisons are summarized in Table 4.

3.5. Microstructural Analyses. The typical SEM-EDX at magnitude of $\times 50$ and $\times 2000$ of cellular concrete is shown in Figure 7 . At $\times 50$ of SEM, it showed that at fractured surface of cellular concrete had many spherical bubbles with 150$500 \mu \mathrm{m}$ in the matrix of cellular concrete. Figure 7 (a) showed the SEM image of cellular concrete after 28 days of 50V0BA (without BA) and Figures 7(b)-7(e) showed the SEM image of cellular concrete containing BA, where it can be observed that cellular concrete had many air voids from foam agent. Size and number of air voids in 50V0BA had close to BA cellular concrete because it used the same foam content. Use of BA did not change the shape and the size of artificial air pores. Cellular concretes incorporating with BA were inconsistently formed of particle and were more porous than the control cellular concrete. It can be seen that the porous cellular concrete increases with an increase in the BA content. It can be explained that the porous behavior is relatively reduced in density of cellular concretes [21]. At $\times 2000$ of SEM, it can be seen that the microstructure morphology of fracture surface of cellular concretes was rough surface due to hydration products $\left(\mathrm{CSH}, \mathrm{Ca}(\mathrm{OH})_{2}\right.$, and ettringite). The 50V0BA had the denser surface than that of BA cellular concrete because BA had high porous particle. 


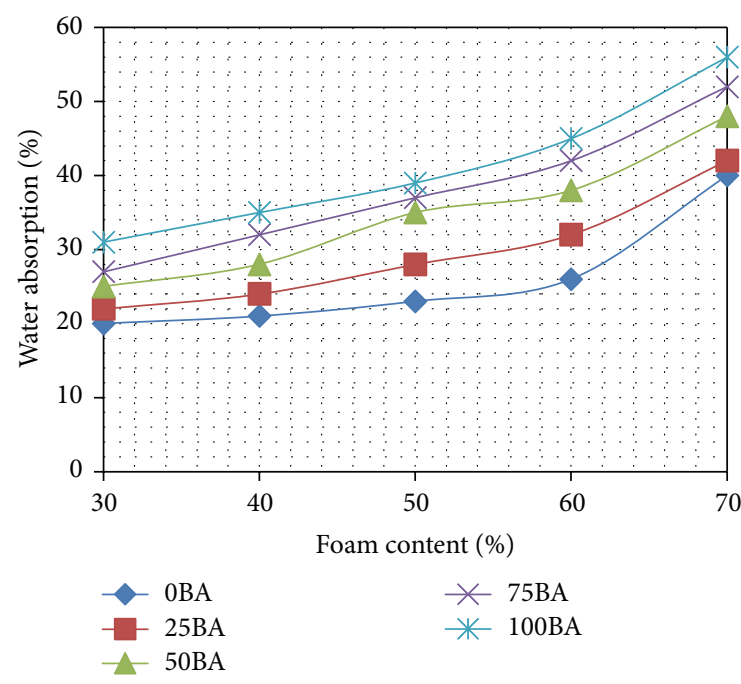

(a) 7 days

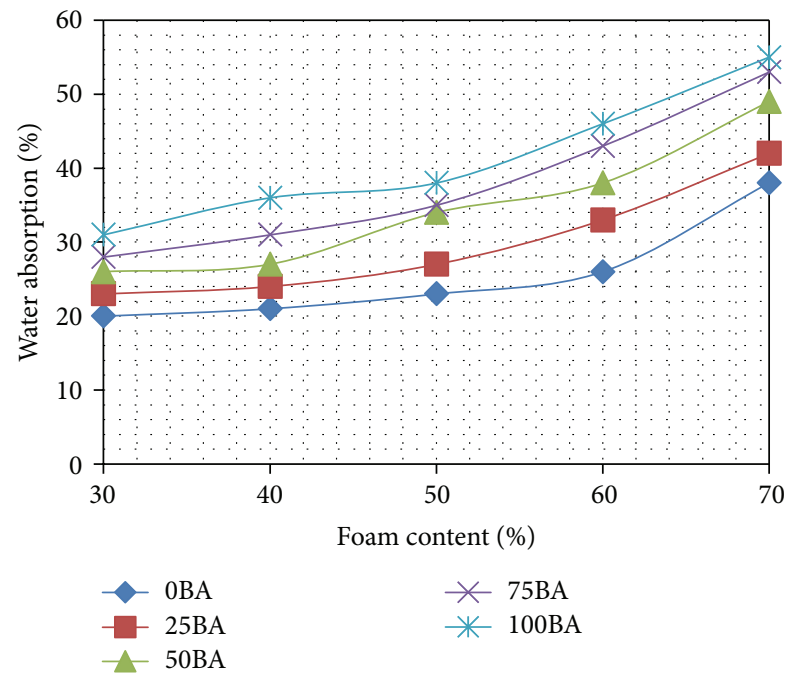

(b) 14 days

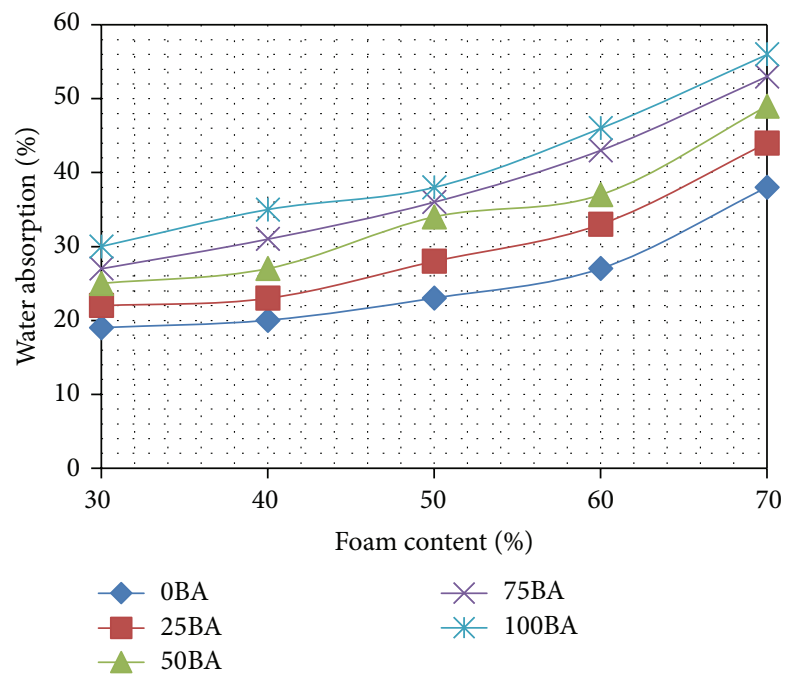

(c) 28 days

FIGURE 5: The water absorption of cellular concrete.

According to Ordinary Portland Cement (OPC), BA from Mae Moh power plant contained large amount of $\mathrm{CaO}$ and $\mathrm{SiO}_{2}$ [22]. Therefore, the results of the EDX analysis of cellular concrete confirm the presence of $\mathrm{Ca}$ and $\mathrm{Si}$ as major elements and the elements of $\mathrm{Fe}$ and $\mathrm{Mg}$ are present as minor elements. In addition, it was found that the increasing of the BA content had a little effect on the chemical reaction of cellular concrete because BA had large particle for reaction with $\mathrm{Ca}(\mathrm{OH})_{2}$ and it was also used as fine aggregate [11]. A ratio of $\mathrm{CaO}$ and $\mathrm{SiO}_{2}$ $(\mathrm{Ca} / \mathrm{Si})$ was often used to characterize the $\mathrm{CSH}$ in concrete where the higher $\mathrm{Ca} / \mathrm{Si}$ ratio gave the higher compressive strength. From Table 1, it was found that $\mathrm{CaO}$ and $\mathrm{SiO}_{2}$ of Ordinary Portland Cement (OPC) and BA were $65.00 \%$ and $20.62 \%$ and $11.48 \%$ and $46.02 \%$, respectively. Thus the $\mathrm{Ca} / \mathrm{Si}$ ratios of 50V0BA, 50V25BA, 50V50BA, 50V75BA, and $50 \mathrm{~V} 100 \mathrm{BA}$ were $3.15,1.91,1.15,0.63$, and 0.25 , respectively. It can be seen that use of higher BA replacement decreased the $\mathrm{Ca} / \mathrm{Si}$ ratio and compressive strength of cellular concrete was related to the decrease in $\mathrm{Ca} / \mathrm{Si}$ ratio too.

3.6. Predicting the Compressive Strength, Water Absorption, and Density Using Multiple Regression Techniques. The nonlinear regression models were performed under SPSS version 15 as (1). The best fit of the data was determined to predict compressive strength, water absorption, and density of cellular concretes containing bottom ash. Classical statistical method was employed for nonlinear regression models and the various possible equations were tried to find the appropriate equation based on the absolute fraction of variance $\left(R^{2}\right)$ results that estimates the proportion of the total variation in the series using (2). In addition, the root mean square (RMS) error and mean absolute percentage (MAPE) error were 


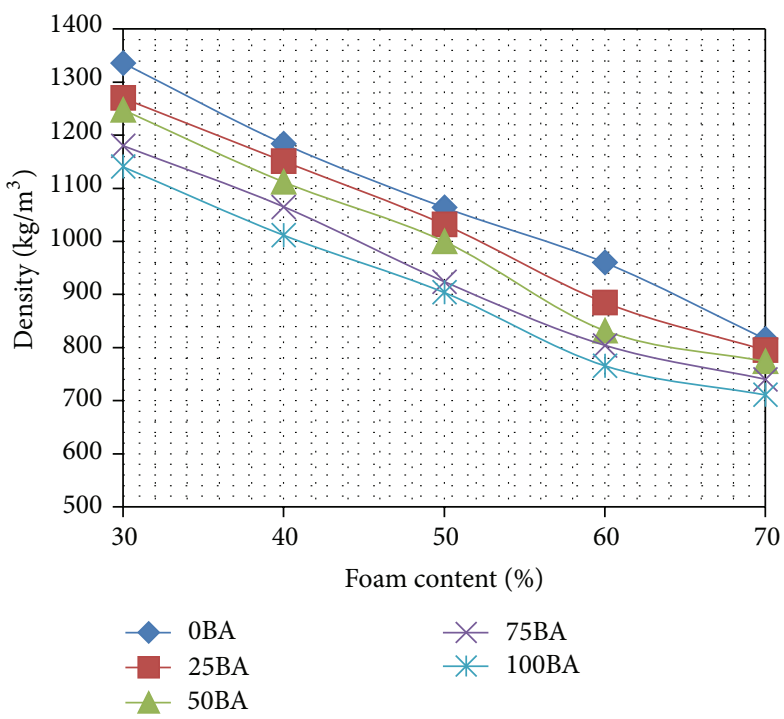

(a) 7 days

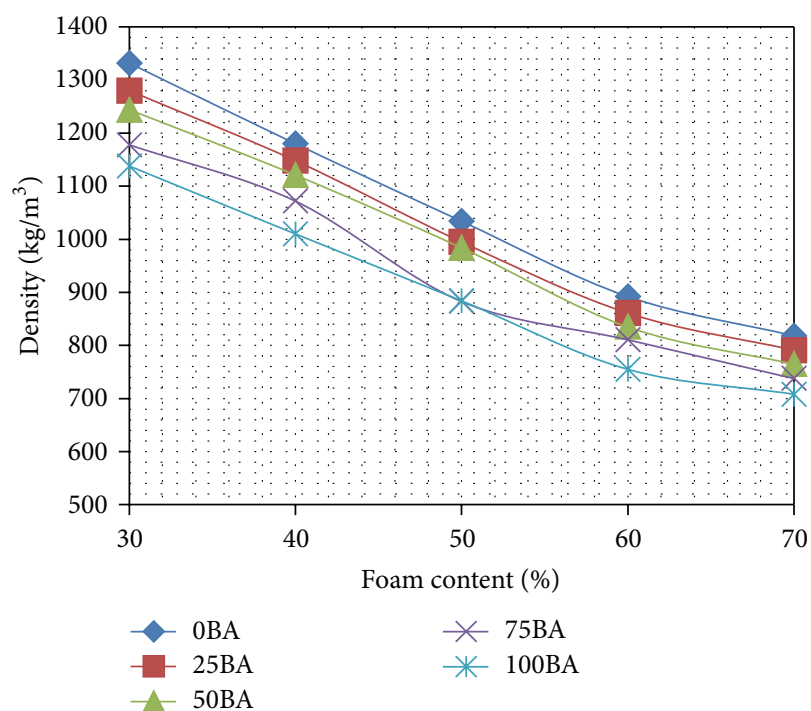

(b) 14 days

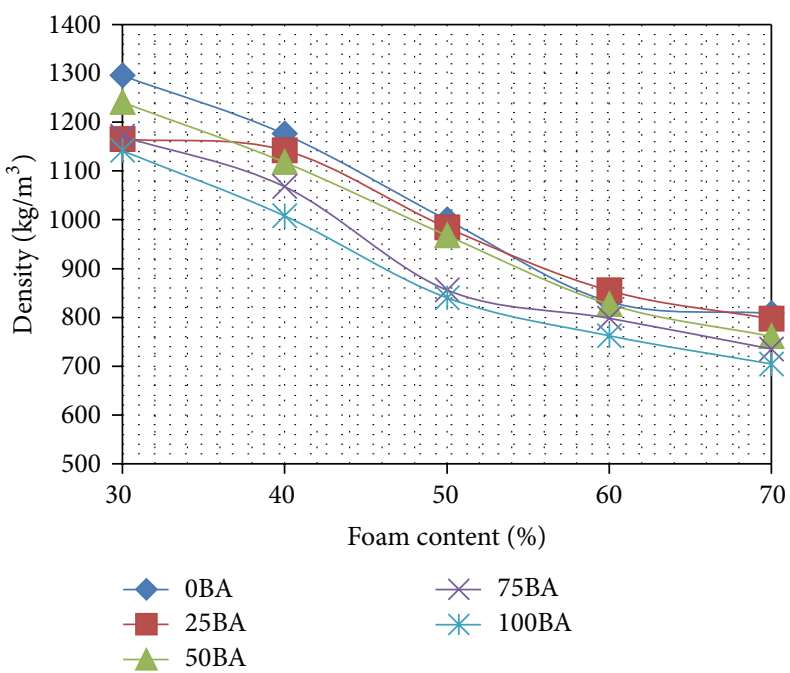

(c) 28 days

FIGURE 6: The density of cellular concrete.

used to measure the variation using (3) and (4), respectively. Consider

$$
\begin{aligned}
Y= & a+a_{1} x_{1}+a_{2} x_{2}+a_{3} x_{3}+a_{4} x_{4}+a_{5} x_{5}+a_{6} x_{6} \\
& +a_{7} x_{1}^{2}+a_{8} x_{2}^{2}+a_{9} x_{3}^{2}+a_{10} x_{4}^{2} \\
& +a_{11} x_{5}^{2}+a_{12} x_{6}^{2}+a_{13} x_{1} x_{2}+a_{14} x_{1} x_{3} \\
& +a_{15} x_{1} x_{4}+a_{16} x_{1} x_{5}+a_{17} x_{1} x_{6} \\
& +a_{18} x_{2} x_{3}+a_{19} x_{2} x_{4}+a_{20} x_{2} x_{5} \\
& +a_{21} x_{2} x_{6}+a_{22} x_{3} x_{4}+a_{23} x_{3} x_{5} \\
& +a_{24} x_{3} x_{6}+a_{25} x_{4} x_{5}+a_{26} x_{4} x_{6} \\
& +a_{27} x_{5} x_{6}
\end{aligned}
$$

$$
\begin{aligned}
R^{2} & =\frac{\sum_{i=1}^{N}\left(P_{i}-\overline{P_{i}}\right)\left(M_{i}-\overline{M_{i}}\right)}{\sqrt{\left[\sum_{i=1}^{N}\left(P_{i}-\overline{P_{i}}\right)^{2}\right]\left[\sum_{i=1}^{N}\left(M_{i}-\overline{M_{i}}\right)^{2}\right]}}, \\
\text { RMS } & =\sqrt{\frac{1}{N} \sum_{i=1}^{N}\left|P_{i}-M_{i}\right|^{2}}, \\
\text { MAPE } & =\frac{1}{N} \sum_{i=1}^{N} \frac{\left|P_{i}-M_{i}\right|}{P_{i}} \times 100,
\end{aligned}
$$

where $P_{i}$ is the predicted value of $i$ th pattern, $\overline{P_{i}}$ is the average predicted value of $i$ th pattern, $M_{i}$ is the actual value of $i$ th pattern, $\bar{M}_{i}$ is the average actual value of $i$ th pattern, and $N$ is the number of patterns.

In this study, the volume of cement $\left(x_{1}\right)$, sand $\left(x_{2}\right)$, water $\left(x_{3}\right)$, foam content $\left(x_{4}\right)$, bottom ash $\left(x_{5}\right)$, and age $\left(x_{6}\right)$ 

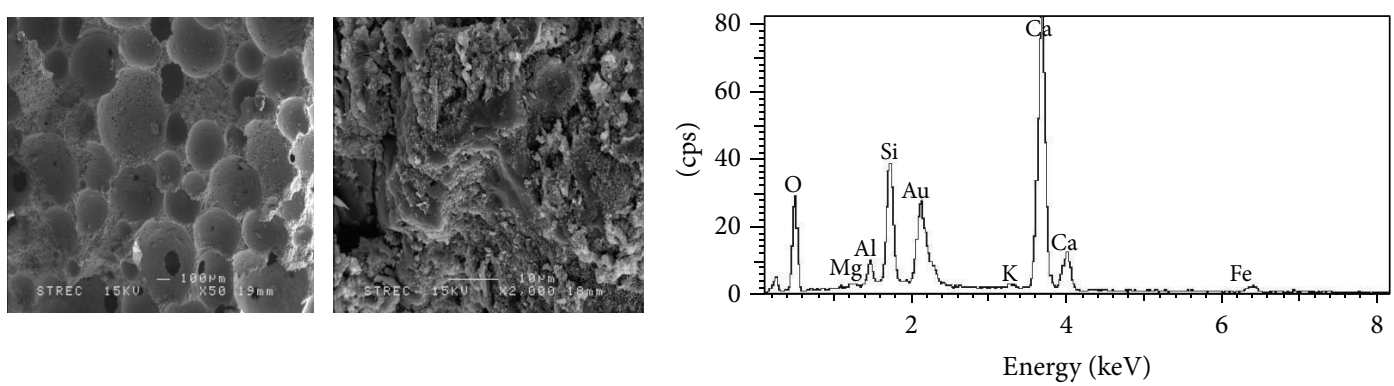

(a) $50 \mathrm{~V} 0 \mathrm{BA}$
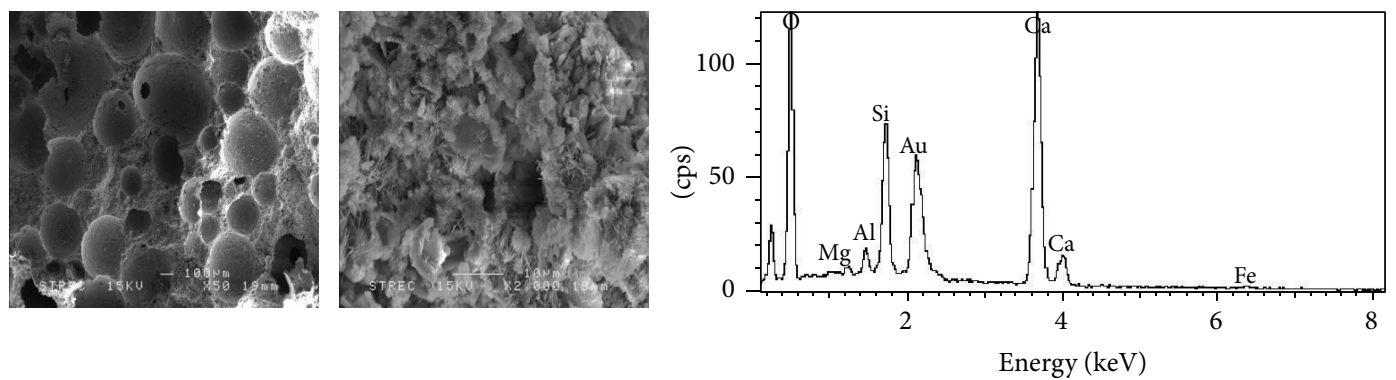

(b) $50 \mathrm{~V} 25 \mathrm{BA}$
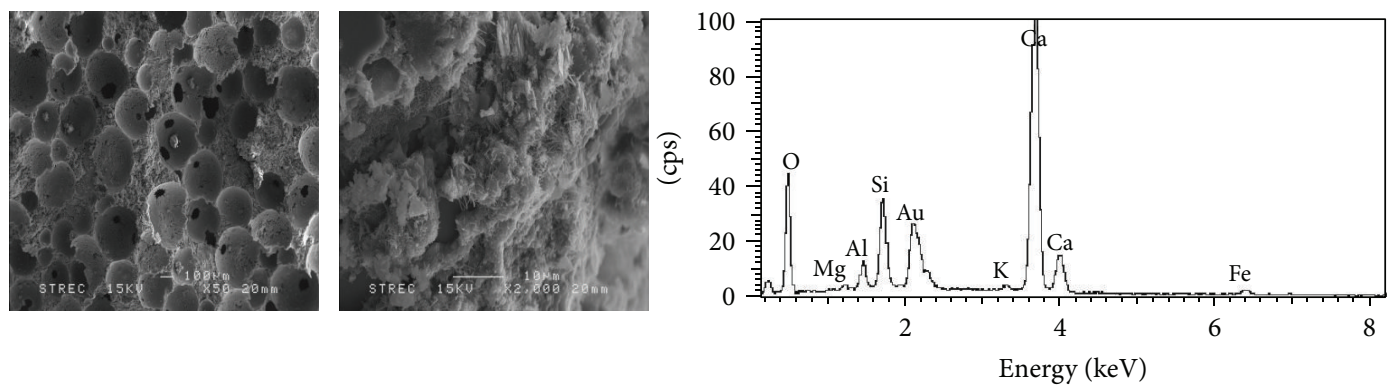

(c) $50 \mathrm{~V} 50 \mathrm{BA}$
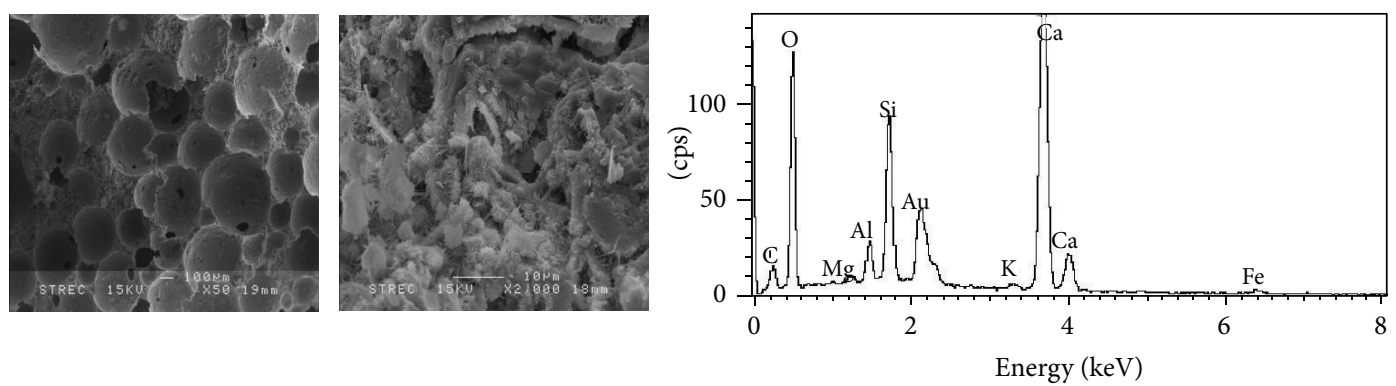

(d) $50 \mathrm{~V} 75 \mathrm{BA}$
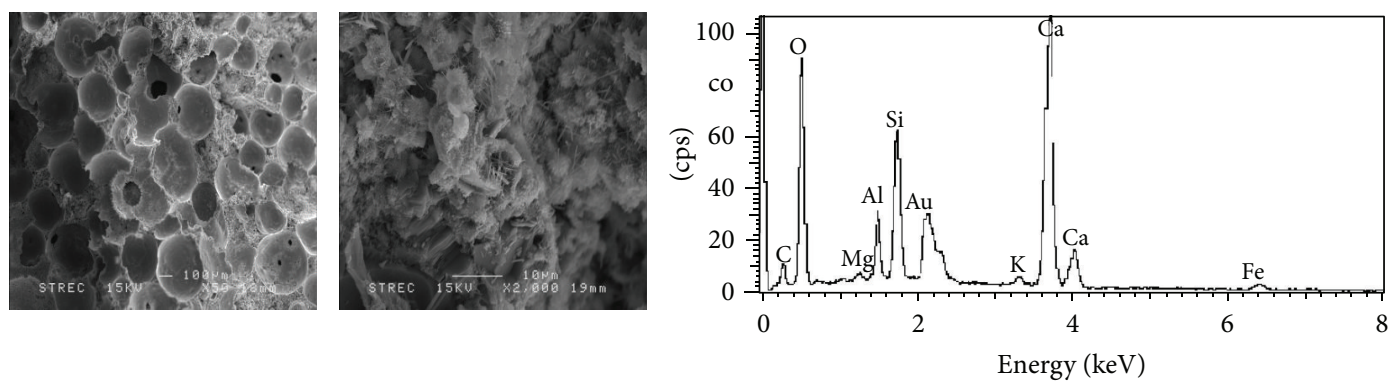

(e) $50 \mathrm{~V} 100 \mathrm{BA}$

Figure 7: SEM image and EDX spectrum of cellular concrete after 28 days. 
TABLE 4: Comparison between cellular concrete and other materials.

\begin{tabular}{lccc}
\hline Description & Compressive strength (MPa) & Density $\left(\mathrm{kg} / \mathrm{m}^{3}\right)$ & Water absorption $(\%)$ \\
\hline Aerated lightweight concrete & & & $300-500$ \\
(TIS 1505-1998) class 2 & 2.5 & $701-800$ & 30 \\
(TIS 2601-2013) class 8 & 2.0 & $801-900$ & 25 \\
(TIS 2601-2013) class 9 & 2.5 & $901-1000$ & 23 \\
(TIS 2601-2013) class 10 & 2.5 & $1001-1200$ & 23 \\
(TIS 2601-2013) class 12 & 2.5 & $1201-1400$ & 23 \\
(TIS 2601-2013) class 14 & 5.0 & 1650 & 20 \\
Commercial clay brick (in Thai) & $2.0-3.0$ & & 40 \\
\hline
\end{tabular}

TABLE 5: The input variables used in nonlinear regression models.

\begin{tabular}{lcc}
\hline Input variables & Minimum & Maximum \\
\hline Cement (by volume), $x_{1}$ & 0.062 & 0.175 \\
Sand (by volume), $x_{2}$ & 0 & 0.215 \\
Water (by volume), $x_{3}$ & 0.126 & 0.343 \\
Foam content (by volume), $x_{4}$ & 0.3 & 0.7 \\
Bottom ash (by volume), $x_{5}$ & 0 & 0.215 \\
Age (day), $x_{6}$ & 7 & 28 \\
\hline
\end{tabular}

TABLE 6: Statistical performance of proposed regression models.

\begin{tabular}{lccc}
\hline Nonlinear regression models & $R^{2}$ & RMSE & MAPE \\
\hline Compressive strength & 0.99493 & 0.08151 & 3.33669 \\
Water absorption & 0.99670 & 0.56786 & 1.50650 \\
Density & 0.99348 & 14.73598 & 1.07225 \\
\hline
\end{tabular}

had significant influence on the compressive strength, water absorption, and density of cellular concrete. Therefore, these six important input parameters were taken into account in the proposed nonlinear regression models. The limit values of input variables used in regression models are listed in Table 5. The details of the best expression equations for the compressive strength, water absorption, and density of cellular concrete using nonlinear regression techniques are given as (5), (6), and (7), respectively.

The nonlinear regression models were evaluated via statistical parameters as seen in Table 6. Based on absolute fraction of variance $\left(R^{2}\right)$, it was found that the nonlinear regression technique gives a high degree of accuracy where $R^{2}$ of the nonlinear regression models are higher than 0.99. In addition, the root mean square (RMS) error and mean absolute percentage (MAPE) error of compressive strength, water absorption, and density of cellular concrete were $0.08151,056786,14.73598$ and $3.33669 \%, 1.50650 \%$, and $1.07225 \%$, respectively. Figures $8-10$ demonstrated that the nonlinear regression was reasonably highly capable of generalizing between the input parameters variables and the output response. Consider

Compressive strength $(\mathrm{MPa})$

$$
\begin{aligned}
= & 17218.66-272213 x_{1}-246505 x_{2}+242078.9 x_{3} \\
& -28700.7 x_{4}-327519 x_{5}-0.21929 x_{6}
\end{aligned}
$$

$$
\begin{aligned}
& +56701.74 x_{1}^{2}+186147.4 x_{2}{ }^{2}-396672 x_{3}{ }^{2} \\
& +11435.29 x_{4}{ }^{2}+209709.4 x_{5}{ }^{2}-0.00063 x_{6}{ }^{2} \\
& +335143.9 x_{1} x_{2}+318630.6 x_{1} x_{3} \\
& +272458.9 x_{1} x_{4}+308200.1 x_{1} x_{5} \\
& +0.730102 x_{1} x_{6}+110436.4 x_{2} x_{3} \\
& +243536.3 x_{2} x_{4}+410634.9 x_{2} x_{5} \\
& +7.434676 x_{2} x_{6}-253026 x_{3} x_{4}+280612.4 x_{3} x_{5} \\
& -4.78157 x_{3} x_{6}+326210 x_{4} x_{5}+0.110857 x_{4} x_{6} \\
& +8.228497 x_{5} x_{6},
\end{aligned}
$$

Water absorption (\%)

$$
\begin{aligned}
= & 302875.2-936182 x_{1}-2667696 x_{2}+978052 x_{3} \\
& -568808 x_{4}-2962800 x_{5}+0.466288 x_{6} \\
& +512554 x_{1}{ }^{2}+3055733 x_{2}{ }^{2}-287101 x_{3}{ }^{2} \\
& +266562.2 x_{4}{ }^{2}+4053092 x_{5}{ }^{2}+0.000225 x_{6}{ }^{2} \\
& +4887007 x_{1} x_{2}-1780599 x_{1} x_{3}+867523.8 x_{1} x_{4} \\
& +5326411 x_{1} x_{5}-22.3514 x_{1} x_{6}-915991 x_{2} x_{3} \\
& +2588109 x_{2} x_{4}+7054651 x_{2} x_{5}-15.2013 x_{2} x_{6} \\
& -968535 x_{3} x_{4}-1138688 x_{3} x_{5}+21.40973 x_{3} x_{6} \\
& +2870581 x_{4} x_{5}+0.083734 x_{4} x_{6}-21.8526 x_{5} x_{6},
\end{aligned}
$$

Density $\left(\mathrm{kg} / \mathrm{m}^{3}\right)$

$$
\begin{aligned}
= & -161981-7568416 x_{1}+5710310 x_{2} \\
& +794080.4 x_{3}+268847.1 x_{4}+5422624 x_{5} \\
& -585.922 x_{6}+15649.19 x_{1}{ }^{2}+15173410 x_{2}{ }^{2} \\
& +16463903 x_{3}{ }^{2}-96259.7 x_{4}{ }^{2}+28294298 x_{5}{ }^{2} \\
& +0.022099 x_{6}{ }^{2}+27792847 x_{1} x_{2}-1647790 x_{1} x_{3}
\end{aligned}
$$




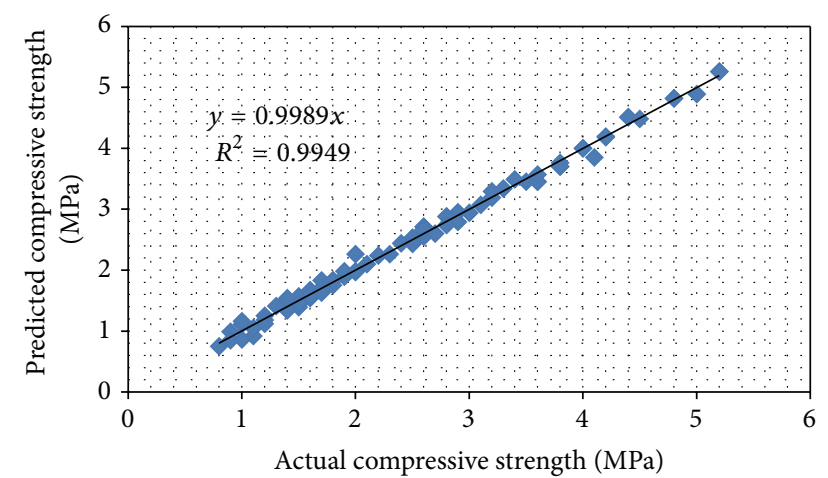

Figure 8: Performance of the compressive strength by nonlinear regression model.

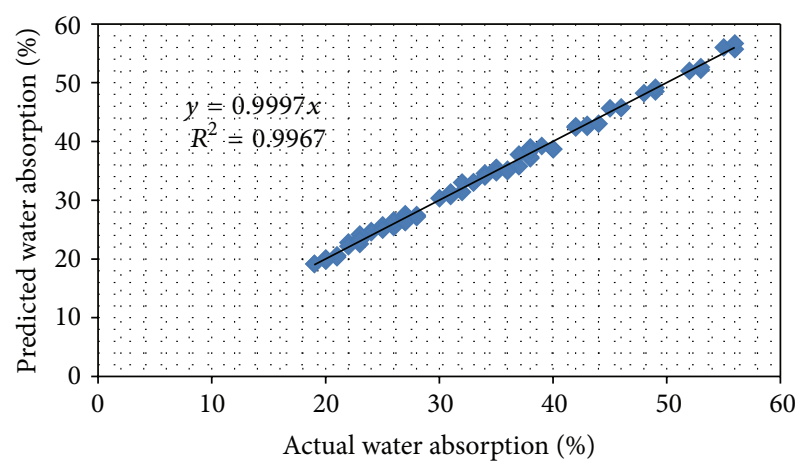

FIgURE 9: Performance of the water absorption by nonlinear regression model.

$$
\begin{aligned}
& +7307366 x_{1} x_{4}+27585862 x_{1} x_{5}-223.943 x_{1} x_{6} \\
& -6611945 x_{2} x_{4}+42750751 x_{2} x_{5} \\
& +626.9418 x_{2} x_{6}+95381.23 x_{3} x_{4} \\
& +999.1555 x_{3} x_{6}-6533201 x_{4} x_{5} \\
& +591.7785 x_{4} x_{6}+450.7238 x_{5} x_{6}
\end{aligned}
$$

when $x_{1}$ is cement (by volume), $x_{2}$ is sand (by volume), $x_{3}$ is water (by volume), $x_{4}$ is foam content (by volume), $x_{5}$ is bottom ash (by volume), and $x_{6}$ is age (day).

\section{Conclusions}

From the experimental results on evaluating the feasibility of utilizing BA from Mae Moh power plant as a fine aggregate in cellular concrete, it can be concluded as follows:

(1) The cellular concrete containing the BA exhibited higher porosity than those of the control concrete and resulted in higher water requirement for achieving workability of cellular concrete. Compressive strength, absorption, and density depended on foam content, percent sand replacement by BA, cement content, and curing age.

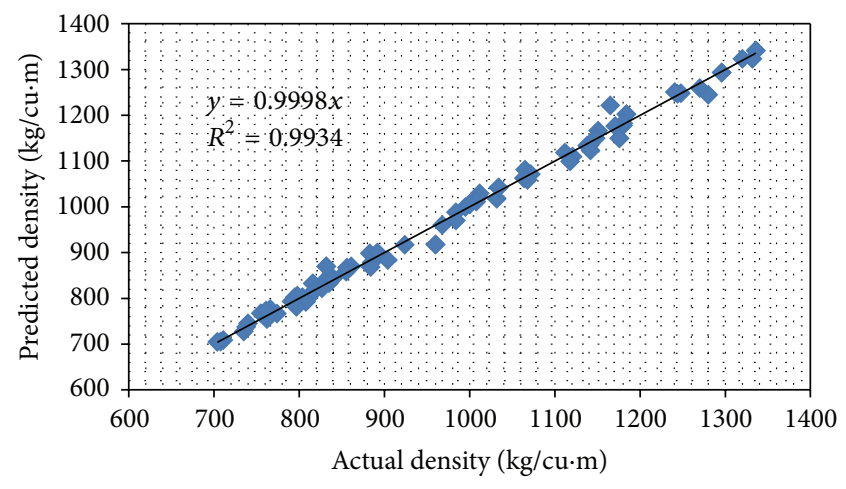

FIGURE 10: Performance of the density by nonlinear regression model.

(2) The optimum replacement of BA in cellular concrete was $25 \%$ by volume of sand and used $50 \%$ of foam content, where it gave compressive strength, density, and water absorption of $2.8 \mathrm{MPa}, 984 \mathrm{~kg} / \mathrm{m}^{3}$, and $28 \%$, respectively. In addition, it was closed to class 10 of TIS standard. Moreover, the resultant properties of the optimum mix are greater than typical clay brick in Thailand's construction industry.

(3) The nonlinear regression technique can be used to predict the compressive strength, water absorption, and density of cellular concrete because it gave a high absolute fraction of variance with a low mean absolute percentage error and root mean square error.

\section{Conflict of Interests}

The authors declare that there is no conflict of interests regarding the publication of this paper.

\section{Acknowledgment}

The authors would like to acknowledge the Concrete and Computer Research Unit, Faculty of Engineering, Mahasarakham University for providing facilities and equipment.

\section{References}

[1] K. Ramamurthy, E. K. Kunhanandan Nambiar, and G. Indu Siva Ranjani, "A classification of studies on properties of foam concrete," Cement and Concrete Composites, vol. 31, no. 6, pp. 388-396, 2009.

[2] A. J. Hamad, "Materials, production, properties and application of aerated lightweight concrete: review," International Journal of Materials Science and Engineering, vol. 2, no. 2, pp. 152-157, 2014.

[3] J. B. Hernández-Zaragoza, T. López-Lara, J. Horta-Rangel et al., "Cellular concrete bricks with recycled expanded polystyrene aggregate," Advances in Materials Science and Engineering, vol. 2013, Article ID 160162, 5 pages, 2013.

[4] P. J. Tikalsky, J. Pospisil, and W. MacDonald, "A method for assessment of the freeze-thaw resistance of preformed foam 
cellular concrete," Cement and Concrete Research, vol. 34, no. 5, pp. 889-893, 2004.

[5] D. G. Snelson and J. M. Kinuthia, "Characterisation of an unprocessed landfill ash for application in concrete," Journal of Environmental Management, vol. 91, no. 11, pp. 2117-2125, 2010.

[6] H. K. Lee, H. K. Kim, and E. A. Hwang, "Utilization of power plant bottom ash as aggregates in fiber-reinforced cellular concrete," Waste Management, vol. 30, no. 2, pp. 274-284, 2010.

[7] Y. Bai and P. A. M. Basheer, "Influence of furnace bottom ash on properties of concrete," Proceedings of the Institution of Civil Engineers: Structures and Buildings, vol. 156, no. 1, pp. 85-92, 2003.

[8] Y. Bai and P. A. M. Basheer, "Properties of concrete containing furnace bottom ash as a sand replacement material," in Proceedings of the International Conference on Structural Faults and Repair, London, UK, July 2003.

[9] Y. Bai, F. Darcy, and P. A. M. Basheer, "Strength and drying shrinkage properties of concrete containing furnace bottom ash as fine aggregate," Construction and Building Materials, vol. 19, no. 9, pp. 691-697, 2005.

[10] H. K. Kim and H. K. Lee, "Use of power plant bottom ash as fine and coarse aggregates in high-strength concrete," Construction and Building Materials, vol. 25, no. 2, pp. 1115-1122, 2011.

[11] C. Jaturapitakkul and R. Cheerarot, "Development of bottom ash as pozzolanic material," Journal of Materials in Civil Engineering, vol. 15, no. 1, pp. 48-53, 2003.

[12] P. E. Regan and A. R. Arasteh, "Lightweight aggregate foamed concrete," The Structural Engineer, vol. 68, no. 9, pp. 167-173, 1990.

[13] E. K. Kunhanandan Nambiar and K. Ramamurthy, "Fresh state characteristics of foam concrete," Journal of Materials in Civil Engineering, vol. 20, no. 2, pp. 111-117, 2008.

[14] E. K. K. Nambiar and K. Ramamurthy, "Sorption characteristics of foam concrete," Cement and Concrete Research, vol. 37, no. 9, pp. 1341-1347, 2007.

[15] R. Kasemchaisiri and S. Tangtermsirikul, "Use of bottom ash as fine aggregate for self-compacting concrete," in National Convention on Civil Engineering, MAT049, pp. 277-283, Bangkok, Thailand, 2008.

[16] T. Y. Lo, W. C. Tang, and H. Z. Cui, "The effects of aggregate properties on lightweight concrete," Building and Environment, vol. 42, no. 8, pp. 3025-3029, 2007.

[17] K. Jitchaiyaphum, T. Sinsiri, C. Jaturapitakkul, and P. Chindaprasirt, "Cellular lightweight concrete containing highcalcium fly ash and natural zeolite," International Journal of Minerals, Metallurgy and Materials, vol. 20, no. 5, pp. 462-471, 2013.

[18] E. K. K. Nambiar and K. Ramamurthy, "Influence of filler type on the properties of foam concrete," Cement and Concrete Composites, vol. 28, no. 5, pp. 475-480, 2006.

[19] Ministry of Industry, "Autoclaved aerated lightweight concrete element," Thai Industrial Standard 1505-1998, Thai Industrial Standard, Bangkok, Thailand, 1998.

[20] Ministry of Industry, "Aerated lightweight concrete," Thai Industrial Standard 2601-2013, Ministry of Industry, Bangkok, Thailand, 2013.

[21] N. Narayanan and K. Ramamurthy, "Structure and properties of aerated concrete: a review," Cement and Concrete Composites, vol. 22, no. 5, pp. 321-329, 2000.

[22] P. Chindaprasirt, C. Jaturapitakkul, W. Chalee, and U. Rattanasak, "Comparative study on the characteristics of fly ash and bottom ash geopolymers," Waste Management, vol. 29, no. 2, pp. 539-543, 2009. 

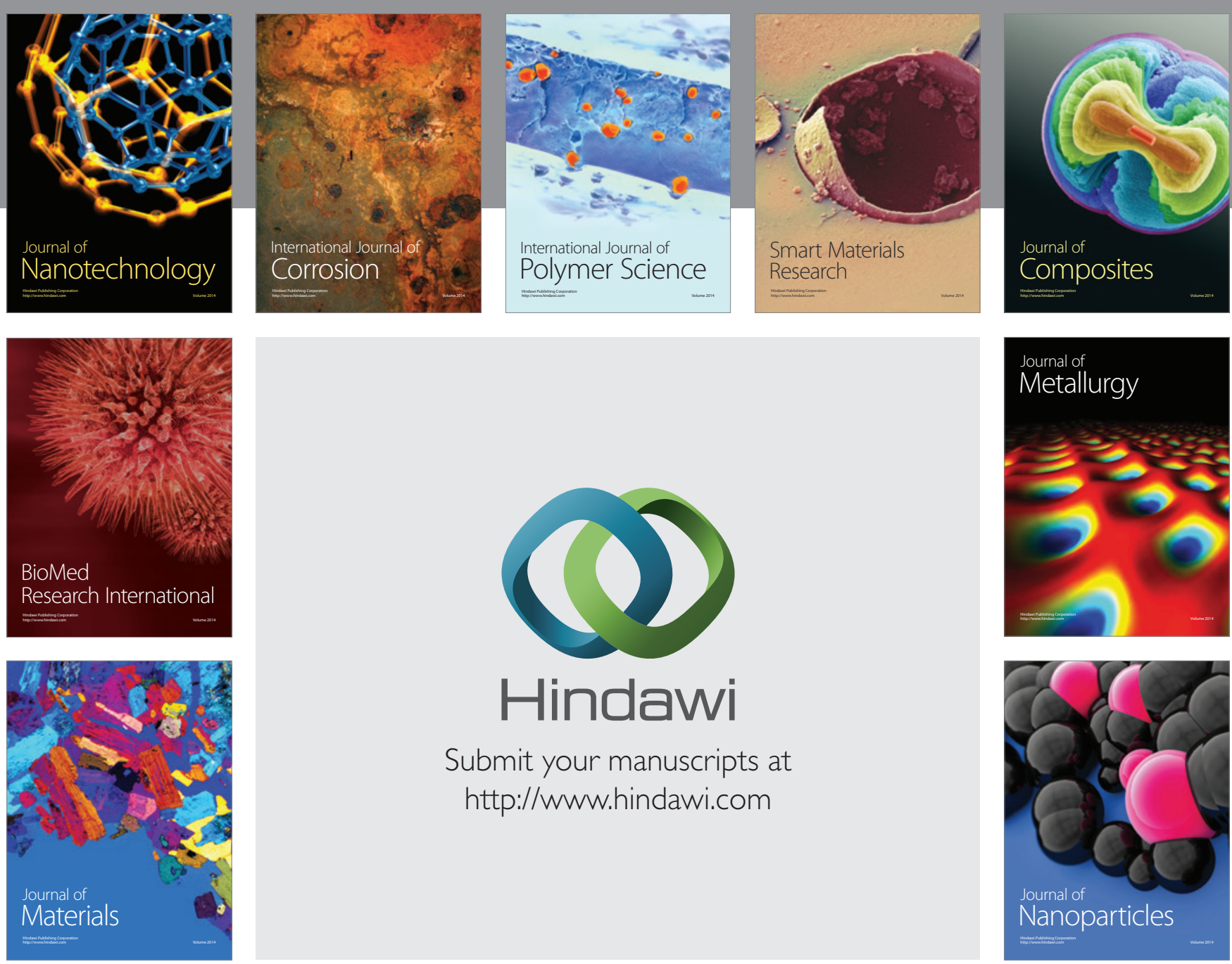

Submit your manuscripts at http://www.hindawi.com
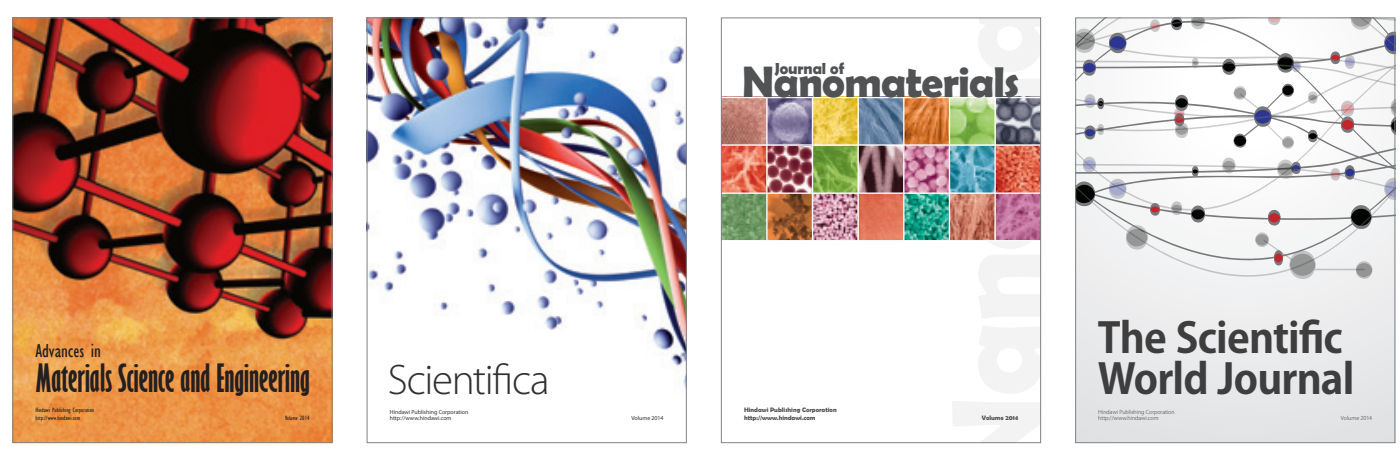

\section{The Scientific World Journal}
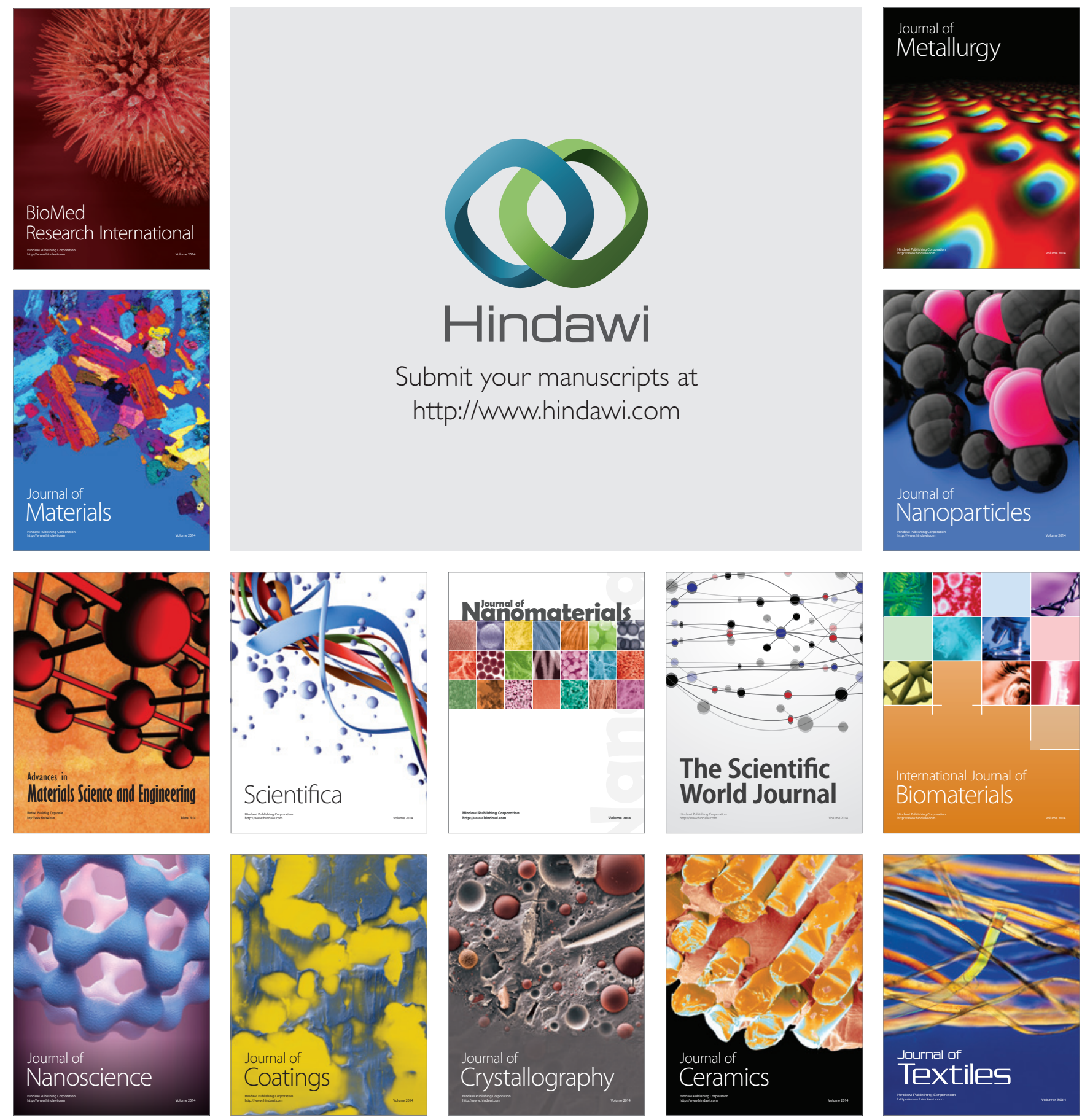